\title{
LAS CONDICIONES CLIMÁTICAS Y MARÍTIMAS COMO FACTORES DE LOCALIZACIÓN DEL TURISMO HISTÓRICO ALICANTINO
}

\section{José Fernando Vera Rebollo}

El presente trabajo versa sobre la importancia que ha tenido el turismo histórico para el posterior desarrollo de la figura del municipio turístico. En este sentido, la práctica totalidad de los núcleos del litoral alicantino, con especial significación vacacional en la actualidad (Denia, Benidorm, Jávea, Altea, Santa Pola, Torrevieja, Villajoyosa y la propia capital), cuentan con una larga tradición como lugares de veraneo que, en algún caso, arranca desde su origen, como se constata en Torrevieja, frecuentada en su mayor parte por la población de su entorno comarcal.

La impronta paisajística (núcleos de veraneo, casetas, balnearios, etc.) y la trascendencia socioeconómica del veraneo histórico, contrastan tanto cualitativa como cuantitativamente con las formas creadas por el turismo de masas. En efecto, en algunas poblaciones litorales se asiste al tránsito de una función de descanso estival, complementaria de una economía primaria, a una turística que, con sus subsectores vinculados, domina la economía y desplaza, a veces de modo absoluto, a las actividades consideradas como tradicionales. Paralelamente, en dichas poblaciones aparece un crecimiento urbano espectacular, motor de la consolidación de un nuevo tipo de municipio con problemática y definición particulares, cuyas repercusiones económicas y territoriales trascienden el marco de los términos municipales y determinan unos nuevos espacios organizados por el turismo, marco referencial que [162] deberá tenerse en cuenta a la hora de abordar el estudio de dichas funciones así como las conexas (ocio, etc.) y el planteamiento de soluciones para la ordenación territorial.

\section{MANIFESTACIONES DEL TURISMO HISTÓRICO}

Conviene señalar en principio que el turismo histórico no debe identificarse únicamente con el veraneo selectivo. En efecto, se ha podido constatar que la costumbre de la temporada de baños se encontraba profundamente arraigada en el modo de vida de las poblaciones rurales del entorno costero ${ }^{1}$. Pero la impronta espacial de un veraneo precario económica y temporalmente no puede compararse a la que desarrolla el turismo de élite, cuya plasmación más conocida son las villas de vacaciones, complementadas en su momento con las desaparecidas instalaciones balnearias.

Existe una clara vinculación del veraneo con la balneoterapia ${ }^{2}$, favorecida extraordinariamente por la mejora de la red de comunicaciones, especialmente el ferrocarril. Junto a ello se intenta desarrollar la idea del descanso invernal, manifestada por la preocupación cientifista del último tercio del siglo XIX de prodigar las excelencias de Alicante como estación de ocio, bajo los auspicios de la administración y de prohombres locales, que vieron en el clima alicantino una hipotética fuente de riqueza, comparable a la de las estaciones invernales de la costa mediterránea francesa, como Niza, Cannes, etc. Ciertamente la preocupación oficial cristalizó en una serie de concursos donde se presentaron memorias a veces de notable envergadura por parte de médicos e higienistas vinculados a la ciudad, en la que estaba latente la idea expresada de convertir Alicante en una residencia invernal. No obstante, no debemos atribuir mayor importancia al intento, ya que en buena parte los proyectos no pasaron de tales, mientras que el veraneo tradicional vio cada vez más acrecentar su importancia, sobre todo con la construcción de las carreteras litorales y el tendido del ferrocarril, que están en la base del éxito de algunos núcleos, como es el caso de Alicante y Torrevieja y, en menor medida, Santa Pola. [163]

La idea del turismo como nueva realidad queda patente en la concepción de 
planteamientos urbanísticos con una indudable visión de futuro, que, de acuerdo con las ideas del momento, se convierten al mismo tiempo en antecedente de los modernos conjuntos de urbanización en forma de ciudad-jardín, como es el caso de la «Ciudad Prieto», que pretendió levantarse en un espacio de $12 \mathrm{Km}^{2}$ comprendido entre el Cabo de la Huerta y la Albufereta y toda la playa de San Juan. La idea data de 1933, con proyecto de urbanización obra del arquitecto Pedro Muguruza que, interrumpido por la Guerra Civil, no se desechó en la inmediata postguerra. Esta iniciativa del alcalde Carbonell surge en razón de la gran afluencia de veraneantes que recibía la capital, así como de las perspectivas de aprovechamiento de la referida playa. Y el plan mereció desde sus inicios el respaldo político de la Segunda República, a través del Ministro de Obras Públicas, Indalecio Prieto.

En la misma línea de apoyo a nuevas realizaciones, se enmarca la cesión de terrenos para un proyecto de urbanización en Jávea, que afectaba al espacio comprendido entre el barrio de Triana y la planicie del Arenal (concesión realizada por el ministro de Hacienda Joaquín Chapaprieta, en 1935, y cuyo proyecto de urbanización data de 1936) ${ }^{3}$.

En la década de 1940-50 el panorama del turismo no se altera más que en la renovación de las formas de ocupación temporal (casetas) de las playas, que paulatinamente se van convirtiendo en viviendas de edificación permanente, al amparo en muchos casos, de concesiones administrativas de ocupación temporal de la zona marítimo-terrestre. Ello da lugar a la aparición de núcleos de veraneo en lugares como la playa de Guardamar y El Pinet (Elche), muy contrastados con el urbanismo de calidad que se pretendía en los diseños citados anteriormente. Será ya en el siguiente decenio cuando se produzca el tránsito a una nueva situación.

\section{LA CLIMATOTERAPIA EN LA SEGUNDA MITAD DEL SIGLO XIX Y PRINCIPIOS DEL XX: ALICANTE ESTACIÓN INVERNAL}

El aprovechamiento higienista del clima en la capital [164] se sustenta en las propias condiciones de situación y topografía que favorecen la suavidad del mismo, al amparo de los flujos de componente Norte, en función del retablo montañoso que ciñe a la ciudad, lo que significa una posición a sotavento, resguardada de los vientos fríos invernales. Además, no carece de importancia la vecindad del Mediterráneo, mar de aguas templadas cuyo cerramiento y caldeamiento se intensifica en la amplia rada que queda delimitada por los cabos de la Huerta y Santa Pola. Este conjunto de factores a los que se unen la posición latitudinal y el alejamiento de la zona depresionaria del Mediterráneo Occidental, así como la escasa nubosidad y alto índice de insolación, determinan una temperatura media para el mes de enero de $11^{\circ} \mathrm{C}$, con reducida amplitud térmica. Por contra, no es tan favorable el dato de la humedad relativa, ya que la intensa evaporación que determina la proximidad del mar, supone una media anual del $65 \%$, si bien esta humedad, combinada con las ya citadas suavidad y constancia de las temperaturas, resulta favorable para la cura de determinadas enfermedades.

Se aplicaba la climatoterapia de acuerdo con la opinión hipocrática, según la cual se reconoce al clima la capacidad de influir en el curso de ciertas enfermedades, al variar las condiciones que favorecen su desarrollo. El auge de esta corriente motivó la aparición en ciertos lugares de instalaciones de este tipo, que fueron clasificadas en aquellas fechas por Fonssagrives ${ }^{4}$, con referencia al elemento estacional y a la localización: Alicante se considera como invernal marítima, con una temperatura templada en invierno a la que se unían las condiciones ventajosas propias del ambiente marino.

Ante la necesidad de dar a conocer las excelencias climatológicas de la ciudad, que la hacían idónea como residencia de invierno, se realizó un esfuerzo a través de la prensa periódica $\mathrm{y}$ con publicaciones de folletos en varios idiomas, celebraciones de fiestas, etc., que cristalizan con la creación de una Comisión para la Propaganda del Clima de Alicante ${ }^{5}$. Los folletos propagandísticos dedicaban particular atención a la calidad de la escena urbana ${ }^{6}$, el ambiente 
placentero de la ciudad, sus equipamientos hoteleros y de restauración, las diversiones, etc., a la vez que se analizan los datos del [165] clima en relación a la terapéutica apuntada. A esta labor se unió la desarrollada por médicos e higienistas que se plasma en una serie de libros o memorias cuyo eje central es el análisis de las condiciones climáticas y, en algunos casos, higiénicas, sanitarias y de equipamiento. Estos autores ponen de relieve las cualidades terapéuticas del clima de Alicante, al que Sánchez Santana, entre otros, define como suave, ozónico, constante, húmedo y de presión con escasas variaciones ${ }^{7}$, que lo hacen especialmente indicado para aquellas patologías del aparato respiratorio que se relacionan con la atmósfera, de entre las cuales destaca la tuberculosis pulmonar. Asimismo, el clima de Alicante, por su elevada humedad y temperaturas moderadas, conviene a los tuberculosos, a los que padecen de escrófula y, en general, para todos los procesos crónicos bronco- pulmonares, así como para las perturbaciones neuróticas ${ }^{8}$.

La idea de convertir Alicante en residencia invernal conllevaba la realización de mejoras relativas a la higiene y equipamiento, cuya situación era bastante precaria ya que en la segunda mitad del siglo XIX, si se atiende a lo expuesto por los autores señalados. En esta línea Sánchez Santana ${ }^{9}$ advertía que elementos positivos tales como la situación, la topografía, el clima, los alrededores agradables, el invierno sin fríos ni variaciones, etc., deben acompañarse de unas condiciones higiénicas y sociales: alcantarillado, pavimentación de las calles, construcción de modernas viviendas, hoteles y chalés, la alimentación, así como los problemas que plantea el suministro de agua a la población. En efecto, los caudales procedentes de La Alcoraya resultaban insuficientes y, en ocasiones, no potables. Tenían una dotación en 1880 estimada en 129.600 litros cada 24 horas, para una población cifrada en 30.000 habitantes, a los que se añadían unas 1.000 personas de población flotante. Todo esto obliga a pedir una dotación de 14 litros por habitante y día como suficiente y a plantear alternativas de traída de aguas de otros lugares (Canal del Cid, Torremanzanas, Sax y Villena, Algar).

Por su parte, Parreño llega a proponer que, además de las condiciones higiénicas señaladas, el éxito de la residencia invernal debía apoyarse en la creación de una [166] verdadera ciudad de ocio «como las opulentas estaciones francesas (...) una población juguetona, alegre, espléndida, como Niza y Menton, y su triunfo como estación invernal está asegurado» ${ }^{10}$, lo cual da idea del tipo de visitantes que se intentaba atraer.

Pero, sin duda, uno de los proyectos más interesantes es la construcción de un Sanitarium donde se aprovecharían las condiciones idóneas del clima. Sus instalaciones se ubicarían en la playa de Babel, por las mejores condiciones de aireación y la existencia de una corriente que sería aprovechada para la evacuación de residuos. ${ }^{11}$ Se trata de un precedente de las grandes instalaciones hoteleras, cuya financiación debía hacerse por un sistema de acciones y que tiene como base un turismo de motivación terapéutica, al menos en su origen, y en buena parte de élite. Ello enlaza con otra de las ideas de mayor relevancia en el tema de la promoción tradicional del invierno en Alicante, como es la orientación hacia una clientela de lujo y de alto poder adquisitivo.

Las favorables circunstancias económicas que propició el comercio del vino, en los años que rigió el tratado con Francia, hacen de Alicante una residencia de invierno para familias acomodadas de la propia provincia, a las que se unen las provenientes de Madrid y Norte de España. Esta corriente se prolonga, con cierta intensidad, hasta los años veinte del siglo actual. Se llegó a pensar en la ciudad como punto de cita de la aristocracia europea, que llegaría a ser, según Parreño, como el veraneo para la costa cantábrica. De ello se desprende que si bien en el turismo de invierno subyacía una motivación terapéutica, la élite supo apropiarse el concepto y convertir en lugares de ocio las estaciones de salud.

En el caso de Alicante nunca llegaría a cuajar el proyecto de residencia de invierno por la falta de empeño en la acción, como señala Figueras Pacheco ${ }^{12}$. Ello lo corrobora la publicación 
Alicante turismo, de 1928: era necesario algo más que el clima y el paisaje. Pero la propia dinámica del veraneo propició la concentración de los esfuerzos en la auge de la temporada de baños. Así, con la idea de fomentar el turismo se crea una sociedad denominada Alicante atracción a fines del decenio de 1920-30. [167]

Aparte de la propia capital provincial, sólo Denia de entre los núcleos de veraneo tradicional tuvo una relativa y modesta importancia como estación invernal, debida más bien a las relaciones que la función comercial de su puerto propiciaba con el extranjero, lo que determinó la construcción de villas de recreo, esencialmente en el sector de Les Rotes.

\section{LA TALASOTERAPIA Y EL AUGE DE LOS BALNEARIOS}

Mayor trascendencia que la función climatoterápica ha tenido hasta finales del decenio de 1950-60 la que se deriva específicamente de la balnearia, centrada casi exclusivamente en Alicante capital y Torrevieja, ya que si bien hubo establecimientos de baños de mar a fines del siglo XIX y primeros años del XX en otras poblaciones marítimas del litoral provincial como Villajoyosa, Benidorm, Denia y Santa Pola, nunca llegaron a tener una trascendencia como la que se documenta en aquellas dos ciudades.

Esta actividad balnearia se desarrolla como consecuencia del auge de la talasoterapia o cura marina de las enfermedades. Los baños de mar se utilizan, según estos criterios, como un medio de curación que necesita método y régimen y que se suelen tomar bajo prescripción facultativa ${ }^{13}$. Se considera que la acción fisioterapéutica de los baños de mar era apropiada para la curación o mejora del curso de ciertas enfermedades ${ }^{14}$.

El verdadero auge de los balnearios se da con el desarrollo y popularización de la función veraniega, apoyada por el ferrocarril y la llegada de la clase media madrileña, que colmaba los establecimientos de baños de mar. Todo ello acelera el proceso de construcción de estas instalaciones a partir de 1860 .

La popularización del uso de los balnearios no supondrá transformaciones radicales en los núcleos, sobre todo si se atiende a que, en la mayor parte de los casos, la ocupación del espacio era sólo temporal. Así, se han analizado expedientes de solicitud de montaje de balnearios en la capital, desde el decenio de 1860-70, lo que permite extraer información relativa a: [168]

-Evolución del número de establecimientos y solicitudes de instalación de los mismos. -Ordenación de la playa y competencias con actividades de asentamiento tradicional.

-Normativa de las instalaciones balnearias y competencias jurídicas entre organismos públicos.

-Tipología de los establecimientos balnearios, formas constructivas y disposición interna.

Por lo que se refiere al punto primero, se conocen los siguientes establecimientos, todos ellos en la playa del Postiguet, en el período comprendido entre los años 1860 y 1960: Diana, La Alianza, La Confianza (antes Neptuno), La Esperanza (Simó), La Rosa, Ferrocarril, Nuevo Neptuno, Las Delicias, El Madrileño, La Florida, La Estrella, El Águila, Playa del Postiguet, El Almirante, Ferrandis y Guillermo y, en el decenio 1920-30, El León y La Alhambra (que sustituye a La Esperanza). No aparecen todas las solicitudes, pero en el período 1880-1910 coexistieron entre ocho y diez de éstos, de los que tres tenían carácter permanente, La Esperanza, La Alianza y Diana. Según Pastor de La Roca ${ }^{15}$, en el decenio 1870-80, eran varios los establecimientos de baños de mar, de los cuales «ocho oportuna y elegantemente dispuestos (...)». También Orozco ${ }^{16}$ señala un total de ocho establecimientos de los cuales dos, Diana y Simó «tienen carácter permanente por ser su base fuertes columnas de hierro». La Guía de Playas y Balnearios da la cifra de nueve de éstos como temporales y los tres citados como estables. Da idea de la importancia que debieron alcanzar el capítulo correspondiente de las Ordenanzas Municipales, de 1898, donde se expresa la normativa que debía observarse en este tipo de 
establecimientos ${ }^{17}$.

La solicitud de más antigüedad encontrada es la del balneario de La Esperanza o de Simó, establecimiento al que le fue concedida la instalación definitiva por R. O. 30-V-1864 ${ }^{18}$, ampliado por R. O. de 10-V-1893. Esta circunstancia de aumento de extensión se refiere al cuerpo del balneario y suele repetirse en el resto de los establecimientos, apoyada en dos motivos: [169]

-A terramiento en el sector contiguo a la playa, por lo que una parte del balneario quedaba fuera de servicio.

-Mayor concurrencia de bañistas en la capital.

Los baños de El Madrileño, de carácter desmontable, debieron construirse en la misma época, si damos crédito a la solicitud que presenta su propietario en 1873, en la que se hace constar que llevan más de diez años instalándose temporalmente. Los de Diana fueron autorizados con carácter permanente por R. O. de 30-VI-1876, mientras que los de La Alianza, propiedad de la Asociación de Obreros y que se montaba para la temporada veraniega en el decenio de $1870-80$, adquieren carácter estable por R. O. 30-VI-1886 ${ }^{19}$, a pesar de la oposición de la Delegación de Marina, con sucesivas ampliaciones en 1889 y 1911. Hubo otros establecimientos como La Confianza, La Estrella y La Rosa, que solicitaron la instalación permanente pero que no llegaron a conseguirlo. Estos montajes estables se hacían sobre pilares de hierro y su objetivo, según consta en el expediente, no era el de abrir fuera de la temporada de baños, sino evitar los gastos que ocasionaban las operaciones de montar y desmontar y la rotura de piezas que se producía en éstas ${ }^{20}$ (20), lo que no excluía la posibilidad de dedicar el edificio, fuera de temporada, a otros usos, como se constata en alguna reclamación, como el de lavadero de pescado y almacén de enseres de pesca.

En el caso de Torrevieja llegaron a existir siete establecimientos al filo de la guerra civil, repartidos entre las playas de El Acequión y antigua de los Bloques ${ }^{21}$, que, si bien no tuvieron la importancia alcanzada por los de la capital, también recibían en los meses veraniegos una intensa afluencia de bañistas, favorecida por el tendido del ferrocarril Albatera-Torrevieja (Ferrocarriles Andaluces) desde 1884. La función veraniega de esta población tiene una gran antigüedad, como corrobora el historiador Montesinos a fines del siglo XVIII ${ }^{22}$ :

Desde tiempo inmemorial, como se ha dicho y se colige de su propio nombre, es muy divertida con su buena alameda, circundada de hermosos y vistosos árboles. A esta torre acuden innumerables gentes de Orihuela, Murcia, Callosa, [170] Catral y otras villas y lugares a bañarse, de forma que en los meses de julio, agosto y septiembre es regular juntarse en este pueblo sobre dos mil personas, por ser este mar muy limpio, muy tranquilo y muy apacible (...)»

En Santa Pola esta misma función tiene cierta importancia ya desde los inicios del siglo XIX, con una diferenciación clara entre la numerosa concurrencia del entorno rural, que veranea en barracas, y las «familias distinguidas» de Elche, que cuentan con chalés propios o alquilan casas en el casco de la población y cuyo centro social de reuniones era los baños de «La Sirena» ${ }^{23}$; lo que nos confirma una vez más en la idea de que en estos establecimientos se combinó la función terapéutica con la de ocio.

También en Benidorm aparece la función veraniega desde el siglo XIX, aunque radicalmente distinta de la imagen que actualmente presenta como una ciudad nueva de ocio, a la medida de un turismo esencialmente internacional y de carácter organizado. La clientela tradicional la formaban familias de Madrid y otras poblaciones interiores, atraídas por los baños de mar en estío. Como resultado de esta función se levantan las primeras villas de vacaciones en la playa de Levante y se construye, en torno a 1870, el balneario de la Virgen del Sufragio, con características similares a las vistas en otras poblaciones ${ }^{24}$. Algo más tarde aparecen los primeros hoteles, como el Bilbaino, que son el preludio de la más importante concentración hotelera provincial. Sin duda hubo en esta población algo esencial que se echa en falta en el resto de núcleos de veraneo tradicional, como es una cierta actividad propagandística, plasmada en hechos 
como la edición de sellos turísticos, sin valor postal, que difundían las excelencias climatológicas y paisajísticas de Benidorm.

En Altea se desarrollaba la función veraniega desde el XIX, aunque no llegaron a existir establecimientos balnearios. En la partida de la Olla y Cap Negret se levantaron villas de recreo por parte de la burguesía local enriquecida o de personalidades que pasaban en ellas los veranos; al mismo tiempo funcionaron algunas fondas y se practicó el alquiler de viviendas para la temporada. [171]

Gran interés reviste desde nuestro punto de vista el tema de las competencias suscitadas por la actividad balnearia con otras actividades, como la pesca, que son el preludio del enfrentamiento entre el turismo y las actividades tradicionales y que ya en el siglo anterior contraponen dos concepciones distintas de aprovechamiento de las playas.

Se ha podido comprobar, a través de las reclamaciones que se presentaban cuando se abría el período de información pública sobre instalación permanente de algunos balnearios, la protesta de los pescadores del bol o jávega de la playa del Postiguet. En el caso de los baños de La Confianza, la reclamación la respaldan cuarenta familias «de la clase más humilde y menesterosa». La respuesta del propietario incide en ese carácter indigente de los que se benefician, así como en la rentabilidad superior del balneario y su fin «social», en el menor espacio ocupado y al hecho de estos pescadores del arte del bol extinguían la pesca ${ }^{25}$. La opinión del Comandante de Marina es contraria también a la pesca del «bol» en el Postiguet, no obstante tampoco es favorable a la instalación del balneario por la necesidad de reservar la playa sin obstáculos para que en invierno puedan vararse las embarcaciones ${ }^{26}$.

Por otro lado, no se autorizó la instalación, ni siquiera estacional, de un balneario en la playa de Babel, por las molestias que podría ocasionar a la zona de servicio del puerto ${ }^{27}$, y fue la misma actividad portuaria la que más tarde motivaría el cierre de algunos balnearios. Del mismo modo, las casetas de pesca y baño que proliferaron en el Postiguet fueron origen de conflictos y, en este sentido, aparece una nota del alcalde en la que señala la multitud de barracas y edificios que se han construido con pilares de mampostería y que se han convertido en tiendas y viviendas permanentes, con infracción del artículo 20 de la Ley de Aguas y que hacen intransitable la playa, por lo que pide que no se concedan más autorizaciones y que se declare la caducidad de las otorgadas ${ }^{28}$.

Pero habrá que esperar hasta los años treinta del presente siglo para ver, enmedio de la conflictividad que [172] creaba la atribución de competencias en materia de instalaciones, una voluntad decidida de organizar por la Delegación Marítima, el emplazamiento y tipo de dichas construcciones dándoles uniformidad y armonía en la construcción y la debida simetría y alineamiento, a la vez que se evitan, las autorizaciones permanentes ${ }^{29}$ y el Ingeniero-Director del Puerto dicta unas normas para el aprovechamiento de la playa ${ }^{30}$. Por último, cabe señalar que la concesión de los permisos de instalación, tanto de casetas como de balnearios, fue motivo de conflicto permanente entre la autoridad de Marina y la Dirección General de Obras Públicas, tanto más si se atiende al hecho de que las edificaciones balnearias se deben por entero a la iniciativa privada, donde se impone un criterio de obtención de rentabilidad inmediata.

\section{$\underline{\text { Sistema de construcción y ensamblaje de los balnearios }}$}

Se levantan sobre columnas de hierro, hincadas en la arena y empotradas en un cimiento de mampostería hidráulica, para mayor seguridad. El conjunto consta de dos partes esenciales:

-La entrada, a modo de puente sobre pilastras, que salva la primera parte de algas y arena, entre la playa y el balneario propiamente dicho. Este puente se adentra bastante en el mar por la escasa importancia del movimiento de las aguas ${ }^{31}$.

-La plataforma, que suele ser rectangular, con un salón central que recibe luz por los frentes y tragaluces. El exterior suele estar rodeado de galería y corredores ${ }^{32}$. 
Pero la solidez de las construcciones no siempre se acompaña de un nivel de calidad y de servicio ${ }^{33}$, sobre todo en los de instalación temporal, si bien el aumento del número de bañistas contribuyó eficazmente a mejorar las edificaciones, así como a dotarlas de servicios de restaurante, aparatos de natación, baños a distinta temperatura y casillas de baño con escalerilla para bajar al mar. Los que tuvieron carácter estable se destacaron por su ornato y alta calidad de servicios que prestaban.

Queda por último hacer mención, una vez más, a la cualidad [173] desmontable de las edificaciones balnearias, aun en los casos de instalación permanente, gracias a la sencillez del sistema de construcción que exigía la concesión de ocupación a título precario, lo que contrasta con las nuevas formas de arquitectura del ocio que, en una nueva fase de la función veraniega, colonizan las playas a perpetuidad.

Las formas arquitectónicas de los establecimientos de baños de mar conjugan las funciones higiénica y de ocio, con unas connotaciones diferentes de las formas tradicionales. En algunos casos estos edificios participan y se impregnan de los valores estéticos imperantes en el momento, pero es sin duda en sus fachadas donde mejor se plasma el carácter de esparcimiento y donde se pretenden representar artificiosamente unas estructuras fastuosas (vide fotorreproducción).

A la hora de valorar esta arquitectura un criterio de interés es el del emplazamiento en que se ubican: suelen aparecer en las playas más próximas o integradas en el núcleo poblacional, en aguas tranquilas y resguardadas. En efecto, los de Alicante se instalan en la playa del Postiguet, cerca de los amplios paseos de palmeras que bordean el frente de mar. De idéntico modo, en Torrevieja, algo más repartidos por la falta de espacio al construirse el puerto, gozan de mayor prestigio los ubicados en las inmediaciones del paseo, donde se montaba la feria en la temporada de baños. También el de Santa Pola, emplazado en la bahía, fue sustituido posteriormente por un restaurante. Por su parte el de Villajoyosa aparecía en la playa más cercana al casco urbano, lo mismo que el de Benidorm.

En definitiva, las edificaciones balnearias han sido una parte integrante, al menos durante la estación estival, del paisaje de algunas poblaciones costeras de la provincia de Alicante, entre las que destaca la propia capital. Elemento paisajístico que, integrado en la función del veraneo, no supuso la destrucción definitiva de las perspectivas de las playas.

La irrupción posteriormente del turismo industrializado aceleró la desaparición de estos establecimientos. [174]

\section{Conclusión}

Es evidente que el estudio de la función turística de las poblaciones marítimas alicantinas que tienen hoy una mayor significación exige, como planteamiento previo, el conocimiento de la función veraniega tradicional, dada su indudable trascendencia paisajística y económica. El veraneo histórico determinaba en su momento unas infraestructuras y formas organizativas que, aunque desarrolladas posteriormente bajo una nueva concepción del ocio industrializado, constituyen la base del actual municipio turístico. Por tanto, la elaboración de tipologías de espacios de ocio en el litoral ha de contemplar necesariamente el factor veraneo histórico por su obvia repercusión en el proceso de ocupación del suelo, formas de urbanización, tipología de las edificaciones, creación de la infraestructura hotelera y, en general, proyección en el modelo de aprovechamiento de los recursos turísticos. 

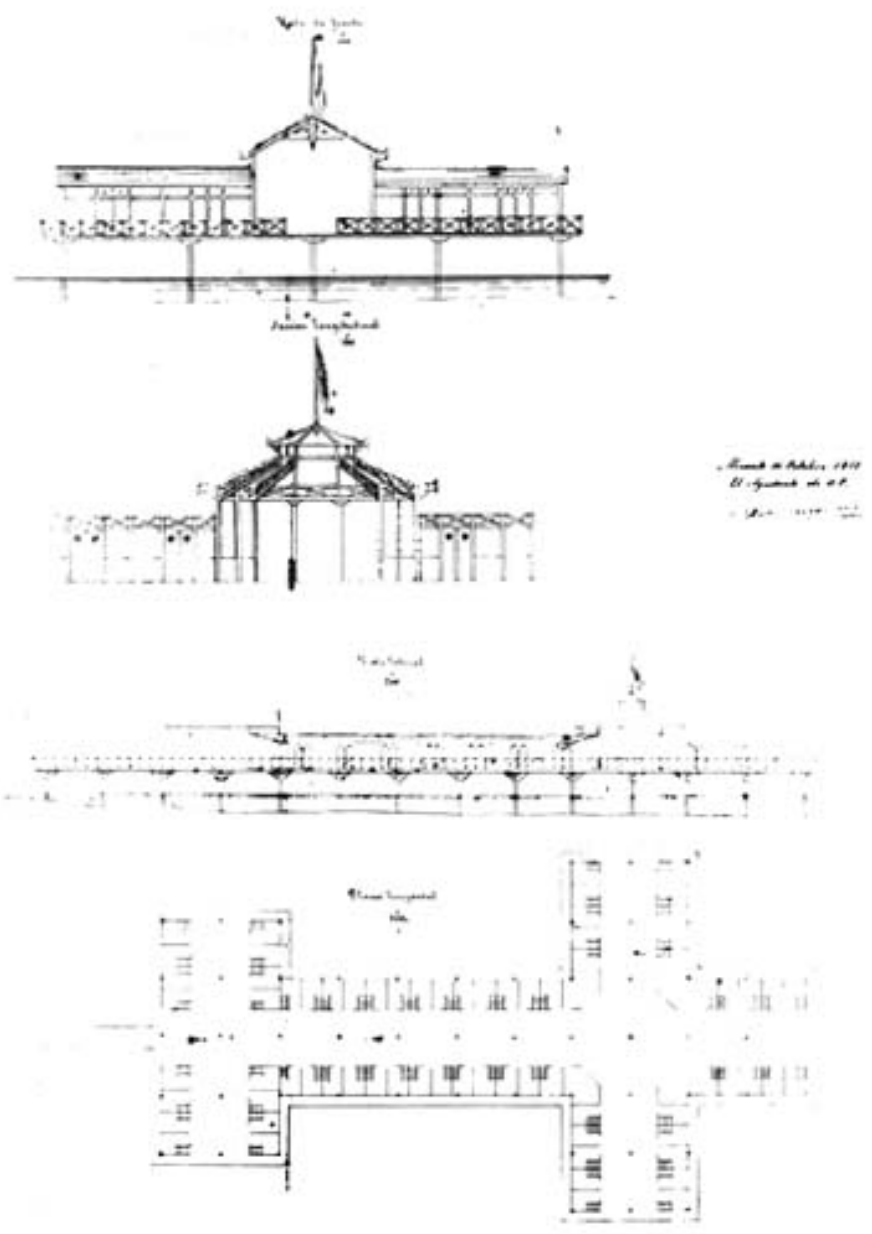

Figura 1.- Alzados y planta del balneario de La Alianza, en la playa alicantina del Postiguet. El edificio, al igual que los otros que se instalaron, es una construcción precaria y semipermanente, sobre pilastras de madera, que incorporaba un simbolismo ornamental de apariencia suntuaria 

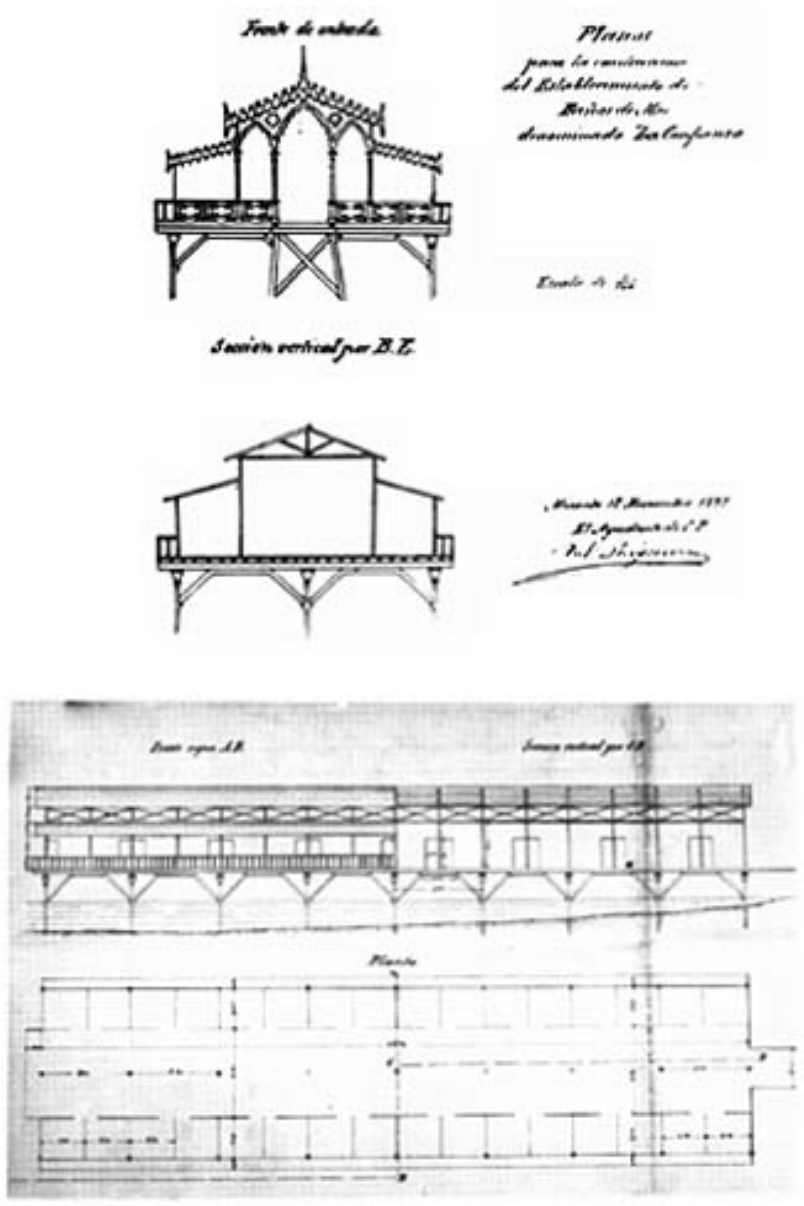

Figura 2.- Alzados y planta del balneario de La Confianza, en la misma playa. La figura muestra el estado inicial de lo que fueron estas instalaciones antes de producirse sus frecuentes ampliaciones

\section{NOTAS}

1 LÓPEZ GÓMEZ, A., «El veraneo tradicional en las costas valencianas. Barraques y casetes de la mar en la Huerta de Gandía», Cuadernos de Geografía, nº 22, Valencia, 1978, pp. 1-28.

2 No se analiza aquí más que la balneoterapia marina, dejando de lado el termalismo. No obstante, cabe resaltar la importancia que tuvieron en su momento lugares donde se aprovechaban aguas minero-medicinales, como Busot, Salinetas de Novelda, Nuestra Señora de Orito, Benimarfull, Baños del Vinalopó, Molinell, Els Banyets d'Agres y San Antón de Orihuela.

3 Sobre proyectos de urbanización vide tesis doctoral del autor, en curso de realización, sobre «Turismo y ordenación del territorio en el litoral alicantino». 13.

4 PARREÑO BALLESTEROS, F., Alicante estación sanitaria, Alicante, Imp. de J. J. Carratalá, 1889, p.

5 Importante es destacar la campaña desarrollada en este sentido por el diario El Imparcial entre 1879 y 1880, con la idea de captar clientela de Madrid, que fue la más numerosa. Se ponía de relieve la calidad de la ciudad y la facilidad del viaje: «catorce horas de ferrocarril bastan para efectuar el cambio», El Imparcial, 25-X-1880. Vide, 
también MANERO, E., Estudios sobre la topografía médica de Alicante, Alicante, Imp. de Carratalá y Gadea, 1883.

6 GADEA PRO, J., Alicante, Résidence d'Hiver, Alicante, Comisión para la Propaganda del Clima, (s. a.)

7 SÁNCHEZ SANTANA, E., Residencia invernal de Alicante, Alicante, Est. Tip. de V. Botella, 1889, p.

9.

8 PARREÑO BALLESTEROS, F., Ob. cit. p. 36 y SÁNCHEZ SANTANA, E., Ob. cit., P. 36-39.

9 SÁNCHEZ SANTANA, E., Ob. cit., p. 77.

10 PARREÑO BALLESTEROS, F., Ob. cit., p. 67.

11 SÁNCHEZ SANTANA, E., Ob. cit., p. 148-157. En el plano del Sanitarium se dibuja una obra de fábrica sobre columnas de hierro, en el que una galería conduce a una rotonda para carruajes, en cuyo centro se instala un cosmógrafo y estación meteorológica. Los ocho pabellones de la obra serían suficientes para albergar cien familias.

12 FIGUERAS PACHECO, F., Alicante, ap. CARRERAS CANDI, F., Geografía General del Reino de Valencia, Barcelona, G. Gili, (s. a.) (1913), p. 352.

13 «La balneoterapia marina exige vigilancia y dirección de un facultativo», PÉREZ MARTÍNEZ, P., Utilidad de los baños de mar, Alicante, Tip. Progreso, 1909, p. 38.

14 Los baños de mar resultan adecuados para la anemia, escrofulismo, tuberculosis en fase atónica, reumatismo (en proceso crónico), etc., por lo que la prescripción facultativa establecía la duración de los baños (el higiénico y de aseo, 15 minutos; el tónico de 2 a 6 minutos y el sedante de 15 a 20 minutos), su número y lo espaciados, así como la época en que debían tomarse que se fijaba del 16 de julio al 15 de agosto (de Virgen a Virgen). El carácter curativo solía traducirse en tomas de novenarios (nueve baños) de los que se recomendaba uno o dos en la temporada. No obstante, resulta curioso como algún médico señala que la gente joven «no repara en las horas que son más convenientes para bañarse, ni en la duración que al baño debe darse». PÉREZ MARTÍNEZ, P. Ob. cit., pp. 50-52. También CORRAL Y MARRA, «Decálogo del bañista», ap. Diario de Alicante, 29-VIII-1907, y MANERO, E., Ob. cit., p. 86.

15 PASTOR DE LA ROCA, J., Guía del alicantino y del forastero en Alicante, Alicante, Imp. de J. Marcili, 1875, p. 88.

16 OROZCO, P. Manual Geográfico-Estadístico de la provincia de Alicante, Alicante, Imp. de A. Reus, 1878 , p. 46.

17 Ordenanzas Municipales de la Ciudad de Alicante, Alicante, Imp. de la Vda. de R. Jordá, 1898, título décimo cuarto, cpt. XCI.

18 Archivo de la Delegación Provincial del Ministerio de Obras Públicas y Urbanismo (en adelante AMOPU), Expediente de autorización para la construcción de balneario, Dirección General de Obras Públicas, Puertos, año 1864.

19 AMOPU, Concesión de permiso para la instalación en la playa del Postiguet de los baños de La Alianza entre los de Simó y de Diana, Dirección General de Obras Públicas, Puertos, junio de 1866.

20 AMOPU, Expediente de solicitud para instalación permanente de los baños de La Confianza, Dirección General de Obras públicas, Puertos, año 1898.

21 VERA REBOLLO, J. F., «Mutaciones espaciales producidas por el turismo en el municipio de Torrevieja»; Investigaciones Geográficas, nº 2, 1984, p. 119.

22 MONTESINOS PÉREZMARTÍNEZ DE ORUMBELLA, J., Compendio Histórico Oriolano, tomo XII. 
23 GOZÁLVEZ PÉREZ, V., Santa Pola, urbanismo, economía, población, Alicante, Círculo de Economía, 1976 , p. 33.

24 Archivo Municipal de Benidorm, Grande establecimiento de baños de mar de la Virgen del Sufragio, (folleto de propaganda) Alicante, Imp. de J. Esplá, 1870

25 AMOPU, Expediente de solicitud para instalación permanente (...) de La Confianza, Dirección General de Obras Públicas, Puertos, año 1898.

26 AMOPU, Expediente de solicitud para instalación permanente del balneario de La Rosa, Dirección General de Obras Públicas, Puertos, 1898.

27 AMOPU, Instancia de D. Matías Escortell para balneario estacional en la playa de Babel, Dirección General de Obras Públicas, Puertos, año 1891.

28 AMOPU, Nota del alcalde al Gobierno Civil, septiembre de 1875.

29 AMOPU, Comunicación de la Delegación Marítima de la Provincia a Ingeniero-Jefe de Obras Públicas, dic. 1933.

30 AMOPU, Expediente por oficio del Ingeniero-Director del Puerto sobre normas de instalación de casetas, año 1934.

31 FIGUERAS PACHECO, F., Ob. cit., p. 370.

32 MANERO, E., Ob. cit., p. 85.

33 ROCA DE TOGORES Y SARAVIA, J. A., «Manual del alicantino y del forastero (Guía de Alicante)», Boletín de la Sociedad Económica de Amigos del País, Alicante, no 10. dic. 1883, pp. 201-331. 